\title{
Prevalence of the Inferior Alveolar Nerve's Anterior Loop and Mandibular Incisive Canal by Use of Cone Beam Computed Tomography (CBCT) in an Iranian Population.
}

Sakhdari $S^{1}$, Hafezi $L^{1}$, Esmaili $M^{2 *}$

${ }^{I}$ Assisstant Professor, Department of Oral and Maxillofacial Radiology, Dental branch of Tehran, Islamic Azad University, Tehran, Iran. ${ }^{2}$ Dentist

\begin{tabular}{l}
\hline ARTICLE INFO \\
\hline Article Type \\
Orginal Article \\
Article History \\
Received: March 2016 \\
Accepted: August 2016 \\
ePublished: July 2016 \\
\hline Keywords: \\
Mental nerve, \\
Anterior loop, \\
Inferior alveolar nerve, \\
Mandibular incisive canal, \\
Cone Beam Computed \\
Tomography
\end{tabular}

\section{ABSTRACT}

Background and Aim: Mental nerve injury is one of the challenges of implant surgeries in the anterior mandibular region, which leads to complications such as paresthesia of the lip and chin. The present study aimed to evaluate the prevalence of the Inferior Alveolar Nerve's (IAN) anterior loop and mandibular incisive canal by use of CBCT.

Methods and Materials:In this descriptive study, 200 high resolution CBCT images of the patients referring to a private oral and maxillofacial radiology center were evaluated. The images were obtained by NewTom Giano unit and were measured in NNT viewer software. Reconstructed panoramic-like images were prepared, and upon the detection of the anterior loop, cross sectional slices were made and dimensions of the anterior loop were calculated by counting the cross sections. In addition, the maximum diameter of the incisive canal was measured, and the location of this diameter was determined on the cross sections relative to dental roots. Data were analyzed by Chi-Square test.

Results: In the 200 evaluated subjects, the prevalence of the anterior loop, with the minimum length of $3 \mathrm{~mm}$, was estimated to be $19 \%$ and the prevalence of the incisive canal was valued to be $87.5 \%$. No significant correlation was detected between the presence of the anterior loop and age, gender, dental status and side of the jaw. Also, no significant association was detected between the presence of the incisive canal and age, gender and dental status $(\mathrm{p}=0.597, \mathrm{p}=0.492, \mathrm{p}=0.643)$ respectively. The maximum diameter of the incisive canal was $5.3 \mathrm{~mm}$ which was located between the first and second premolars.

Conclusion: Considering the results, it seems that evaluation and measurement of the length of the IAN's anterior loop and the diameter of the incisive nerve by CBCT are necessary steps to prevent nerve injuries during surgical procedures in the anterior mandibular region.

Please cite this paper as:

Sakhdari S, Hafezi L, Esmaili M. Prevalence of the Inferior Alveolar Nerve's Anterior Loop and Mandibular Incisive Canal by Use of Cone Beam Computed Tomography (CBCT) in an Iranian population. J Res Dent Maxillofac Sci. 2016;1(3):14-21. 


\section{Introduction:}

One of the challenges of mandibular surgeries such as implant placement in the inter-foraminal area and in the symphysis bone is the inadvertent injury to the Inferior Alveolar Nerve (IAN) and Mental Nerve, which causes paresthesia in the lip and chin. ${ }^{(1)}$ IAN has a complex pathway. This nerve leaves the mandibular corpus at the mental foramen and often forms an anterior loop after traversing a short backwards path before returning into the mandibular bone. ${ }^{(2)}$ The shape, curvature and direction of this terminal portion is highly variable. ${ }^{(3)}$ If the anatomy of this area and the nerve pathway are disregarded, the nerve will be injured during surgery and a wide range of sensory perception disturbances such as paresthesia, anesthesia or even dysesthesia will occur, mainly in the lip and chin. ${ }^{(2,4)}$ Therefore, a safe distance of $5 \mathrm{~mm}$ from the mental foramen should be considered to prevent nerve damage during implant insertion. ${ }^{(5)}$

The part of the IAN that is located anterior to the mental foramen is called the Incisive Nerve, which is comprised of neurovascular bundles that innervate central and lateral incisors, canine and first premolar. ${ }^{(6,7)}$ Formerly, the interforaminal area was considered safe for surgical procedures. However, now it is clear that due to the presence of vital anatomic structures such as incisive nerves and vessels, surgical procedures should be performed cautiously in this area. Currently, paresthesia and bleeding are two common complaints after surgical procedures in the interforaminal region. Therefore, the location and alignment of the mentioned neurovascular structure should be carefully assessed before surgery. (6)

Previously, conventional radiographic techniques such as panoramic radiography were used to assess the anterior loop. Some of the disadvantages of the mentioned technique include limited two-dimensional view, inherent magnification and distortion. ${ }^{(9)}$ In addition, it is impossible to put the patient in the exact previous same position in the panoramic machine. ${ }^{(10)}$

Cone Beam Computed Tomography (CBCT) is a highly efficient imaging modality for the assessment of vital anatomic structures. ${ }^{(6)}$ Moreo- ver, CBCT provides acceptable three-dimensional (3D) views and accessibility to the craniofacial structures in comparison with conventional radiographic techniques. It also has lower radiation dose and occupies less physical space than medical CT. ${ }^{(9,11)}$ CBCT superiorly visualizes the anatomical variations of the IAN and prevents nerve damage and the resultant complications during surgery ${ }^{(9)}$ In addition, the incisive canal is better visualized in CBCT scans in comparison with conventional radiographic techniques, and even when some lengthy incisive canals are invisible on panoramic radiographs, they can be clearly seen on CBCT views. ${ }^{(12)}$

Currently, few studies are available regarding the histology and radiographic views of mandibular anatomic structures. ${ }^{(8)}$

In a study by Apostolakis et al, the incidence of the anterior loop was reported in $48 \%$ of the cases. ${ }^{(13)}$ However, in a report by de OliveiraSantos et al, the incidence of the anterior loops lengthier than $2 \mathrm{~mm}$ was reported in $22-28 \%$ of the subjects. ${ }^{(9)}$ Also, the presence of the incisive nerve (extended from the mental foramen towards the symphysis) was stated to be $83 \%$ in a study by Pires et al. ${ }^{(10)}$ While, in a research by Dalili Kajan and colleagues, the frequency of the incisive nerve was stated in $92.3 \%$ of the subjects and the anterior loop was found in $37 \%$ of the cases. ${ }^{(6)}$ The incidence of the anterior loop was reported to be $71 \%$ and the average diameter of the incisive canal was estimated to be $2.2 \mathrm{~mm}$ by Uchida et al. ${ }^{(14)}$ Due to the high anatomic variations of the IAN's anterior loop and mandibular incisive canal, a definite and safe distance from the mental foramen cannot be accurately decided before implant insertion surgery, without careful observation and assessment of 3D CBCT images. The present research aimed to evaluate the incidence of the IAN's anterior loop and the related factors, and also to determine the maximum diameter of the mandibular incisive canal and its location relative to the anterior teeth in CBCT images of the patients referring to an oral and maxillofacial radiology center. 


\section{Materials and Methods:}

In this cross-sectional descriptive analysis, according to the performed calculations with 95\% confidence interval and considering the deviation (error rate) from the actual prevalence in the society, the sample size was calculated to be 200 patients (400 hemi- mandibles). Patients in need of CBCT scans of the entire mandible for implant insertion, without any pathologic lesion (radiolucent-radiopaque), impacted teeth or history of previous trauma to anterior part of the jaw or around IAN and mental foramen were selected from among the patients referring to a private oral and maxillofacial radiology center in Tehran. The subjects included 100 males and 100 females. Twenty six subjects were completely edentulous and 174 were dentate, with the age range from 21 to 68 years and the mean age of 47 years.

High resolution CBCT images were obtained by NewTom Giano unit (QR SRL Company, Verona, Italy) with a $11 \times 5 \mathrm{~cm}$ field of view (FOV) and exposure parameters of $\mathrm{kVp}=90$, $\mathrm{mA}=10, \mathrm{t}=9 \mathrm{~s}$. All the images were observed on a $356 \times 244 \times 37 \mathrm{~mm}$ Dell Inspiron N5010 Screen with the resolution of $1366 \times 768$ pixels, in a room with proper lighting conditions. Measurements were performed in NNT viewer software. CBCT slices covered $2 \mathrm{~cm}$ distal to the mental foramen. First, panoramic-like reconstructed images were prepared from the axial slice in $1 \mathrm{~mm}$ sections and upon the detection of the anterior loop (it is worth mentioning that, loops lengthier than $3 \mathrm{~mm}$ were considered as the anterior loop), cross-sectional slices with $1 \mathrm{~mm}$ thickness and $1 \mathrm{~mm}$ intervals were prepared. By counting the slices between the most anterior border of the mental foramen (Figure 1)

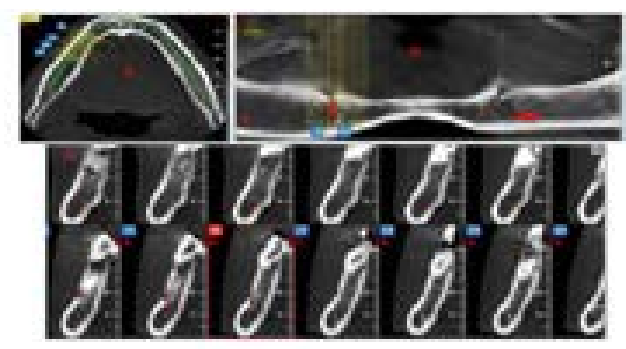

Figure 1 - The most anterior border of the mental foramen (start point of the anterior loop). A) Axial view: B) Reconstructed panoramic view C) Cross sectional view. and the start point of the incisive canal (Figure 2)



Figure 2 - The start point of the incisive canal (terminal portion of the anterior loop). A) Axial view: B) Reconstructed panoramic view C) Cross sectional view.

and by considering the thickness of each slice, the exact dimensions of the anterior loop were calculated for each sample. Two observers simultaneously evaluated the images in NNT viewer software, and they were in agreement regarding the presence or absence of anterior loop and its dimensions.

The maximum diameter (height) of circular or ovoid mandibular incisive canals was also measured, and the location of this diameter was determined on cross-sectional slices relative to dental roots. (Figure 3)

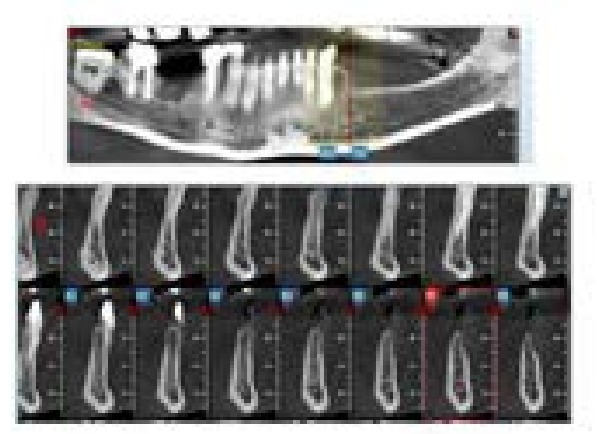

Figure 3 - Measurement of the maximum diameter (height) of the mandibular incisive canal. A) Reconstructed panoramic view B) Cross sectional view.

Data were entered into SPSS software (version 22) and were statistically analyzed by Chi-Square 
test with $95 \%$ confidence interval.

\section{Result:}

The results of the present research which involved 200 CBCT images (including 400 hemimandibles) showed that the prevalence of the IAN's anterior loop, provided that the length of the loop was at least $3 \mathrm{~mm}$, is $19 \%$ (38 cases out of 200 subjects). Sixteen cases were observed on the right side, 15 cases on the left side and 7 cases were observed bilaterally(Table 1).

Table 1 - Prevalence of the IAN's anterior loop based on side

\begin{tabular}{lcc}
\hline Prevalence & Number & $\%$ \\
\hline absence & & \\
\hline right side & 162 & 81 \\
\hline left side & 16 & 8 \\
\hline Bilateral & 15 & 7.5 \\
\hline Total & 7 & 3.5 \\
\hline
\end{tabular}

In 175 cases $(87.5 \%)$, the incisive nerve was definitely observable, which extended form the mental foramen towards the symphysis. The measurements showed that the maximum diameter of the incisive canal was located between the first and second premolars (62\%). (Table 2)

Table 2 - Prevalence of the mandibular incisive nerve based on the related factors (location of the maximum diameter and dental status) in CBCT images

\begin{tabular}{|c|c|c|c|}
\hline & Prevalence & Number & $\%$ \\
\hline \multicolumn{4}{|l|}{ Related factors } \\
\hline \multirow{5}{*}{$\begin{array}{l}\text { Location of the } \\
\text { maximum diameter }\end{array}$} & Between $1^{\text {st }}$ and $2^{\text {nd }}$ premolars & 107 & 62 \\
\hline & Below $1^{\text {st }}$ premolar's root & 20 & 11.2 \\
\hline & Between canine an $1^{\text {st }}$ premolar & 17 & 9.5 \\
\hline & $\begin{array}{l}\text { Uniformly from canine to } 2^{\text {nd }} \\
\text { premolar }\end{array}$ & 31 & 17.3 \\
\hline & Total & 175 & 100 \\
\hline \multirow[t]{3}{*}{ Dental status } & Edentulous & 26 & 13 \\
\hline & Dentate & 174 & 87 \\
\hline & Total & 200 & 100 \\
\hline
\end{tabular}

Table 3 - Correlation between the presence of the IAN's anterior loop and gender, side of the jaw, and dental status in CBCT images

\begin{tabular}{|c|c|c|c|}
\hline Prevalence & & Number & $\%$ \\
\hline \multirow{5}{*}{$\begin{array}{c}\text { Location } \\
\text { of the } \\
\text { maximum } \\
\text { diameter }\end{array}$} & $\begin{array}{l}\text { Between } 1^{\text {st }} \text { and } 2^{\text {nd }} \\
\text { premolars }\end{array}$ & 107 & 62 \\
\hline & $\begin{array}{c}\text { Below } 1^{\text {st }} \text { premolar's } \\
\text { root }\end{array}$ & 20 & 11.2 \\
\hline & $\begin{array}{c}\text { Between canine an } \\
1^{\text {st }} \text { premolar }\end{array}$ & 17 & 9.5 \\
\hline & $\begin{array}{l}\text { Uniformly from } \\
\text { canine to } 2^{\text {nd }} \\
\text { premolar }\end{array}$ & 31 & 17.3 \\
\hline & Total & 175 & 100 \\
\hline \multirow{3}{*}{$\begin{array}{l}\text { Dental } \\
\text { status }\end{array}$} & Edentulous & 26 & 13 \\
\hline & Dentate & 174 & 87 \\
\hline & Total & 200 & 100 \\
\hline
\end{tabular}

Table 4 - Correlation between the presence of the IAN's anterior loop and age in CBCT images

\begin{tabular}{|c|c|c|c|c|c|}
\hline Age & Max & Min & Mean & SD & P-value \\
\hline Left & 67 & 22 & 46.6 & 14.21 & \\
\hline Right & 67 & 25 & 42.75 & 10.71 & 0.505 \\
\hline Bilateral & 60 & 21 & 40.43 & 12.62 & \\
\hline
\end{tabular}

No statistically significant difference was found between males and females, dental status or different age groups in terms of the prevalence of incisive canal.(Tables 5 and 6 )

Table 5 - Correlation between the presence of the mandibular incisive nerve and gender and dental status in CBCT images

\begin{tabular}{|c|c|c|c|c|c|c|}
\hline & & \multicolumn{4}{|c|}{ Side of the anterior loop } & \multirow[b]{2}{*}{ P-value } \\
\hline & & $\begin{array}{c}\text { Absent } \\
\text { anterior loop }\end{array}$ & Right & Left & Bilateral & \\
\hline \multirow{4}{*}{ Age } & Mean & 44.88 & 42.87 & 46.6 & 39.33 & \multirow{4}{*}{0.597} \\
\hline & SD & 11.68 & 11.08 & 14.21 & 13.46 & \\
\hline & Min & 21 & 25 & 22 & 21 & \\
\hline & Max & 68 & 67 & 67 & 60 & \\
\hline
\end{tabular}


No statistically significant difference was found between males and females, left and right sides, dental status or different age groups in terms of the prevalence of anterior loop.(Tables 3 and 4)

Table 6 - Correlation between the presence of the mandibular incisive nerve and age in CBCT images

\begin{tabular}{ccccccc}
\hline & & \multicolumn{4}{c}{ Side of the anterior loop } & \multirow{2}{*}{ P-value } \\
\cline { 2 - 6 } & & $\begin{array}{c}\text { Absent } \\
\text { anterior loop }\end{array}$ & Right & Left & Bilateral & \\
\hline \multirow{4}{*}{ Age } & Mean & 44.88 & 42.87 & 46.6 & 39.33 & \\
\cline { 2 - 6 } & SD & 11.68 & 11.08 & 14.21 & 13.46 & \multirow{2}{*}{0.597} \\
\cline { 2 - 6 } & Min & 21 & 25 & 22 & 21 & \\
\cline { 2 - 6 } & Max & 68 & 67 & 67 & 60 & \\
\hline
\end{tabular}

The minimum diameter of the incisive nerve was estimated to be $0.5 \mathrm{~mm}$ and the maximum diameter was estimated to be $5.3 \mathrm{~mm}$ with the average diameter of $2.04 \pm 1.1 \mathrm{~mm}$. With $95 \%$ confidence interval, the maximum diameter which was located between the first and second premolars was between $1.66 \mathrm{~mm}$ and $2.05 \mathrm{~mm}$. This value was between $2.04 \mathrm{~mm}$ and $3.28 \mathrm{~mm}$ below the root of the first premolar and between $2.58 \mathrm{~mm}$ and $3.49 \mathrm{~mm}$ below the canine and first premolar. The locations of the maximum diameter of the mandibular incisive nerve in CBCT images are presented in Table 7.

\section{Discussion:}

In the present study, the prevalence of the IAN's anterior loop (provided that the loop was at least $3 \mathrm{~mm}$ long) equaled $19 \%$. In earlier studies, the manner of image evaluation and the diagnostic criteria for the anterior loop were dissimilar and these are among the important factors contributing to the controversy in the obtained results.

In a study by de Oliveira-Santos et al in 2011in Brazil, the method of determining the anterior loop's dimensions was similar to that of our research and was performed through counting the number of $1 \mathrm{~mm}$ cross sectional slices. In the mentioned study, the prevalence of the anterior loop with dimensions greater than $2 \mathrm{~mm}$ was calculated to be between $22-28 \%$, which is particularly close to the results of the present research in an Iranian population. They also concluded that the occurrence of the anterior loop was not significantly different between males and females, between two sides of the jaw, or in different age groups. These findings are also in agreement with our results. ${ }^{(9)}$

The findings of the present research differ from the results of the study by Apostolakis et al in 2012. The prevalence of $48 \%$ was reported for the anterior loop in the mentioned study. This difference can be attributed to the manner of evaluation of the anterior loop. However, they found no significant correlation between the presence and absence of the anterior loop and age range of the individuals, which is in agreement with our findings. ${ }^{(13)}$

In 2012, Dalili Kajan and colleagues evaluated the prevalence of the anterior loop and mandibular incisive canal in CBCT images. The prevalence of the anterior loop was estimated to be $40 \%$, and no correlation was declared between the presence of the anterior loop and gender and

Table 7 - Location of the maximum diameter of the mandibular incisive nerve in CBCT images

\begin{tabular}{|c|c|c|c|c|c|}
\hline & & \multicolumn{4}{|c|}{ Location of the maximum diameter } \\
\hline & & $\begin{array}{l}\text { Between } 1^{\text {st }} \text { and } 2^{\text {nd }} \\
\text { premolars }\end{array}$ & $\begin{array}{c}\text { Below } 1^{\text {st }} \\
\text { premolar's root }\end{array}$ & $\begin{array}{l}\text { Between canine } \\
\text { and } 1^{\text {st }} \text { premolar }\end{array}$ & $\begin{array}{l}\text { Uniformly from } \\
\text { canine to } 2^{\text {nd }} \\
\text { premolar }\end{array}$ \\
\hline \multirow{5}{*}{$\begin{array}{l}\text { Diameter } \\
(\mathrm{mm})\end{array}$} & Mean & 1.85 & 2.66 & 3.04 & 1.76 \\
\hline & SD & 1.01 & 1.32 & 0.89 & 0.95 \\
\hline & Min & 0.5 & 1 & 1 & 0.5 \\
\hline & Max & 5 & 5.20 & 5.3 & 3.3 \\
\hline & $\begin{array}{l}95 \% \text { CI for mean } \\
\text { diameter }(\mathrm{mm})\end{array}$ & $(1.66-2.05)$ & $(2.04-3.28)$ & $(2.58-3.49)$ & $(1.41-2.1)$ \\
\hline
\end{tabular}


side of the jaw, ${ }^{(6)}$ which concur with our results. However, they found significant correlation between the presence of the anterior loop and different age groups, as they concluded that the anterior loop is less prevalent in individuals over 40 years of age. ${ }^{(6)}$

Filo et al in 2014 reported the prevalence of $69.73 \%$ for the anterior loop ${ }^{(15)}$, which is extremely higher than the prevalence calculated in our research. The main reason for this difference similar to the differences with the studies by Apostolakis et al ${ }^{(13)}$ and Dalili Kajan et al ${ }^{(6)}$, is the manner of evaluating the anterior loop, since no particular measure as a diagnostic criterion has been determined in the cited research, and the redirections in nerve's path have been simply considered as anterior loops. While in the present study, only the nerve turnings with at least $3 \mathrm{~mm}$ length were measured as anterior loops. In the mentioned study, no significant correlation was detected between the presence and absence of the anterior loop and gender, age, dental status and side of the jaw ${ }^{(15)}$, which is in line with our results.

In a study by Vujanovic-Eskenazi et al in 2014 in Spain, the prevalence of the anterior loop in CBCT images was found to be $48.8 \%$, which is higher than our estimations. ${ }^{(5)}$ This relatively high prevalence can be attributed to the diagnostic criteria for the anterior loop, similar to the studies by Filo et al, ${ }^{(15)}$ Apostolakis et al ${ }^{(13)}$ and Dalili Kajan et al .(6)

The frequency of the anterior loop was estimated $7 \%$ by Jacobs and colleagues, which contradicts the results of the previous studies. Spiral CT was used in the mentioned study with the slice thickness of $2 \mathrm{~mm}$. Since the length of the anterior loop is usually between 2 to $3 \mathrm{~mm}$, it seems that the anterior loop has been missed in many slices. In the above study, no differences were detected among different age groups or between males and females regarding the observation of different anatomic landmarks. ${ }^{(16)}$

In addition, Chen et al in 2012 evaluated the dimensions and location of the anterior loop by CBCT in American and Taiwanese populations and declared that in both populations, the lengthiest anterior loops were visible in the age range between 30 to 39 years. Also, no differences were detected among different age groups regarding the presence of the anterior loop, although in older age groups, American and Taiwanese populations were different. Also, no differences were detected between males and females. ${ }^{(17)}$

Ngeow and colleagues assessed the anterior loop by panoramic radiography among different age groups. Based on the findings of the mentioned study, in older individuals, the probability of the detection of the anterior loop declines due to decreased calcification of the cortical bone. ${ }^{(18)}$

The results of the cited research contradicts the findings of the studies by Chen et al ${ }^{(17)}$, Apostolakis et $\mathrm{al},{ }^{(13)}$ de Oliveira-Santos et al ${ }^{(9)}$, and Jacobs et al ${ }^{(16)}$ and also the results of the present study. Considering that panoramic radiography has lower sensitivity for detection of anatomic landmarks compared to CBCT, increased porosity of the cortical bone due to aging, makes it difficult to detect the canal's boundary in panoramic radiographs.

Kaya et al in 2008 estimated a higher prevalence for the anterior loop in Spiral CT images versus panoramic radiography, and insisted on the importance of 3D imaging for visualization of the anterior loop especially in patients with decreased bone density. ${ }^{(19)}$

In the present study, the incisive canal was observable in $87.5 \%$ of the evaluated individuals and extended to the symphysis area.

The study by Uchida et al in 2009 showed no significant differences between CBCT images and dried skull, in the estimation of the dimensions of the anterior loop and mandibular incisive canal, which denotes the accuracy and validity of CBCT in the assessment of jaw anatomy and also indicates the importance of evaluating the CBCT images before implant surgeries. ${ }^{(14)}$

Pires et al in 2009 evaluated the frequency and dimensions of the mandibular incisive canal by CBCT. ${ }^{(10)}$ The incidence of the mandibular incisive canal was $83 \%$ in their samples, which is similar to our results.

The prevalence of the incisive canal was reported to be $83.5 \%$ in the CBCT images evaluated by Makris et al in $2009,{ }^{(8)}$ which is very close to our findings. They also insisted on the importance of CBCT in implant treatment plans, considering the high frequency of the mandibular incisive canal.

Furthermore, the incidence of the mandibu- 
lar incisive canal was reported to be $92.3 \%$ in the study by Dalili Kajan et al ${ }^{(6)}$, which is close to our estimations. In addition, they concluded that no statistical significant correlations existed between the presence and absence of the incisive canal and factors such as age, gender and side of the jaw, which concurs with our findings. In the mentioned study, the location of the maximum diameter of the incisive nerve was between the canine and first premolar, while we concluded that the maximum diameter was located between the first and second premolars.

Jacobs et al calculated the incidence of $93 \%$ for the incisive nerve ${ }^{(16)}$, although they did not mention the tooth that the maximum nerve diameter was located beneath it.

Moreover, the incidence of the incisive nerve was stated to be $94.4 \%$ by Sahman et al (12). Filo and colleagues observed the incisive nerve in $100 \%$ of their subjects ${ }^{(15)}$.

In a research by Ramesh et al in 2015, the incisive nerve was discernible in $71.6 \%$ of 120 CBCT images. The results of the mentioned study differs from the results of most of the previous studies including our research. Different ethnicity and age group of the studied population and the use of different CBCT units can be the reasons for this difference. However, the average diameter of the incisive nerve was estimated to be 2.578 $\mathrm{mm}$ in the cited research, which is particularly close to the findings of our study. ${ }^{(20)}$

\section{Conclusion:}

Based on the results of this study, the prevalence of mandibular anterior loop was 19\% and the prevalence of incisive canal was $87.5 \%$ in CBCT images. Due to high anatomical variations in the anterior mandible, evaluation of this region with $\mathrm{CBCT}$ seems necessary.

\section{Acknowledgement:}

We are thankful to those who helped us in this article including the research center of Islamic Azad University, Dental Branch of Tehran.

\section{References:}

1. Vazquez L, Saulacic N, Belser U, Bernard JP. Efficacy of panoramic radiographs in the preoperative planning of posterior mandibular implants: a prospective clinical study of 1527 consecutively treated patients. Clin Oral Implants Res 2008;19(1):81-5.

2. Gerlach NL, Meijer GJ, Maal TJ, Mulder J, Rangel FA, Borstlap WA, et al. Reproducibility of 3 different tracing methods based on cone beam computed tomography in determining the anatomical position of the mandibular canal. J Oral and Maxillofac Surg 2010;68(4):811-7.

3. Uchida Y, Yamashita Y, Goto M, Hanihara T. Measurement of anterior loop length for the mandibular canal and diameter of the mandibular incisive canal to avoid nerve damage when installing endosseous implants in the interforaminal region. J Oral Maxillofac Surg 2007;65(9):1772-9.

4. Kim SG, Park SS. Incidence of complications and problems related to orthognathic surgery. J Oral Maxillofac Surg 2007;65(12):2438-44.

5. Vujanovic-Eskenazi A, Valero-James JM, SanchezGarces MA, Gay-Escoda C. A retrospective radiographic evaluation of the anterior loop of the mental nerve: comparison between panoramic radiography and cone beam computerized tomography. Med Oral Patol Oral Cir Bucal 2015;20(2):e239-45.

6. Dalili Kajan Z, Salari A. Presence and course of the mandibular incisive canal and presence of the anterior loop in cone beam computed tomography images of an Iranian population. Oral Radiol 2012;28(1):55-61.

7. Singh N, Jaju PP, Jaju S, Agarwal R. Detection of anatomical variations in mandible by panoramic radiography. J Cranio Max Dis 2014;3(2):95-100.

8. Makris N, Stamatakis H, Syriopoulos K, Tsiklakis $\mathrm{K}$, van der Stelt PF. Evaluation of the visibility and the course of the mandibular incisive canal and the lingual foramen using cone beam computed tomography. Clin Oral implants Res 2010;21(7):766-71.

9. de Oliveira-Santos C, Souza PH, de Azambuja Berti-couto S, Stinkens L, Moyaert K, Rubira-Bullen IR,et al. Assessment of variations of the mandibular canal through cone beam computed tomography. Clin Oral Investig 2012; 16(2):387- 93.

10. Pires CA, Bissada NF, Becker JJ, Kanawati A, Landers MA. Mandibular incisive canal: cone beam computed tomography. Clin implant Dent Relat Res 2012;14(1):67-73.

11. Scarfe WC, Farman AG, Sukovic P. Clinical applications of Cone-Beam Computed Tomography in dental practice. J Can Dent Assoc 2006;72(1):75-80.

12. Sahman H, Sekerci AE, Sisman Y, Payveren M. Assessment of the visibility and characteristics of the mandibular incisive canal: cone beam computed tomography versus panoramic radiography. Int J Oral 
Maxillofac Implants 2014;29(1):71-8.

13. Apostolakis D, Brown JE. The anterior loop of the inferior alveolar nerve: prevalence, measurement of its length and a recommendation for interforaminal implant installation based on cone beam CT imaging. Clin Oral Implants Res 2012;23(9):1022-30.

14. Uchida Y, Noguchi N, Goto M, Yamashita Y, Hanahira T, Takamori H, et al. Measurement of anterior loop length for the mandibular canal and diameter of the mandibular incisive canal to avoid nerve damage when installing endosseous implants in the interforaminal region: a second attempt introducing cone beam computed tomography. J Oral Maxillofac Surg 2009;67(4):744-50.

15. Filo K, Schneider T, Locher MC, Kruse AL, Lubbers HT. The inferior alveolar nerve's loop at the mental foramen and its implications for surgery. J Am Dent Assoc 2014;145(3):260-9.

16. Jacobs R, Mraiwa N, vanSteenberghe D, Gijbels F, Quirynen M. Appearance, location, course, and morphology of the mandibular incisive canal: an assessment on spiral CT scan. Dentomaxillofac Radiol 2002;31(2):322-7.

17. Chen JC, Lin LM, Giest JR, Chen JY, Chen CH, Chen YK. A retrospective comparison of the location and diameter of the inferior alveolar canal at the mental foramen and length of the anterior loop between American and Taiwanese cohorts using CBCT. Surg Radiol Anat 2013;35(1).11-8.

18. Ngeow WC, Dionysius DD, Ishak H, Nambiar P. A radiographic study on the visualization of the anterior loop in dentate subjects of different age groups. J oral Sci 2009;51(2):231-7.

19. Kaya Y, Sencimen M, Sahin S, Okcu KM, Dogan N, Bahcecitapar M. Retrospective radiographic evaluation of the anterior loop of the mental nerve: comparison between panoramic radiography and spiral computerized tomography. Int J Oral Maxillofac implants 2008;23(5):919-25.

20. Ramesh AS, Rijesh K, Sharma A, Prakash R, Kamur A, Karthik. The prevalence of mandibular incisive nerve canal and to evaluate its average location and dimension in Indian population. J Pharm Bioallied Sci 2015;7(Suppl 2):594-6. 